\title{
Designing for conservation outcomes: The value of remnant habitat for reptiles on ski runs in subalpine landscapes
}

Chloe F. SATO ${ }^{\text {a*}}$, Jeff T. WOOD ${ }^{\text {a }}$, Mellesa SCHRODER ${ }^{\mathrm{b}}$, Damian R. MICHAEL ${ }^{\mathrm{a}}$, William S. OSBORNE ${ }^{\mathrm{c}}$, Ken GREEN ${ }^{\mathrm{b}}$ and David B. LINDENMAYER ${ }^{\mathrm{a}, \mathrm{d}}$

a Fenner School of Environment and Society,

The Australian National University,

Canberra, ACT, 0200,

Australia

${ }^{\mathrm{b}}$ Snowy Mountains Region,

National Parks and Wildlife Service,

PO Box 2228,

Jindabyne, NSW 2627,

Australia

c Institute for Applied Ecology,

University of Canberra,

Canberra, ACT, Australia

d ARC Centre of Excellence for Environmental Decisions,

The Australian National University,

Canberra, ACT 0200,

Australia

Email: chloe.sato@anu.edu.au; Phone: +612 6125 8696; Fax: +612 61250757

jeff.wood@anu.edu.au

mel.schroder@environment.nsw.gov.au

damian.michael@anu.edu.au

will.osborne@canberra.edu.au

kenneth.green@environment.nsw.gov.au

david.lindenmayer@anu.edu.au

* Corresponding author

Date of Manuscript Revision: May 20 23, 2014

Manuscript word count (including text, references, tables and captions): 6938 


\begin{abstract}
Subalpine ecosystems are centres of endemism that are important for biodiversity. However, these areas are under threat from the creation, expansion and continued modification of ski runs, activities that have largely negative effects on wildlife. Despite this 5 threat, research on the impacts of ski runs is limited for reptiles - particularly regarding the value of remnant vegetation retained on ski runs. Here we quantify the effects of habitat loss and fragmentation (i.e., patch size, patch isolation and edge effects) on the abundance of a common subalpine lizard and on thermal regimes (a key determinant of lizard distribution) in an Australian ski resort. The number of lizards observed differed significantly with habitat

10 type (ski runs vs. forested areas) and patch isolation, but not patch size. In addition, the edges of patches supported more lizards than any other habitat type. These patterns of lizard distribution can be explained, in part, by the differing thermal regimes in each habitat. Ski runs had significantly higher ground surface temperatures than any other habitat type, precluding their use for a considerable proportion of the activity period of a lizard. In 15 comparison, edges were characterised by lower temperatures than ski runs, but higher temperatures than the core of forested areas, potentially providing a favourable environment for thermoregulation. Based on our results, we conclude that although modified ski runs have a negative effect on lizards, patches of remnant vegetation retained on ski runs are of value for reptiles and their conservation could help mitigate the negative effects of habitat loss caused by ski run creation.
\end{abstract}

Keywords Edge effects; Habitat loss; Habitat fragmentation; Lizard; Metapopulation theory; Skink; Thermal regime 


\section{Introduction}

Habitat loss and fragmentation are primary drivers of biodiversity loss worldwide (Fahrig 2003; Lindenmayer and Fischer 2006). In subalpine landscapes, substantial habitat loss and fragmentation occurs through the construction and expansion of ski resort infrastructure (WWF 2005). The expansion of ski resorts, and modifications undertaken within existing resort boundaries, are a concern as subalpine areas are sensitive but highly biodiverse environments that support many endemic species and communities (Martin 2013; Nagy and Grabherr 2009). Thus, significant disturbance to subalpine areas, coupled with the impacts of climate change (see Spehn et al. 2010; Whetton et al. 1996), may result in the loss of many species from these environments (WWF 2005).

Ski-related disturbances - chiefly associated with ski runs - have largely negative effects on wildlife (Laiolo and Rolando 2005; Negro et al. 2013; Sato et al. 2013a). Ski runs may be particularly detrimental landscape features for wildlife because structural complexity is extremely simplified in these areas. During the construction and annual maintenance of ski runs, native vegetation is cleared, rocks and logs are removed, and slopes are graded to create a smooth skiing surface (Behan 1983; Burt and Rice 2009; Hadley and Wilson 2004; Ries 1996). As a direct or indirect result of these changes, animals inhabiting or dispersing across disturbed ski areas are more susceptible to predation (Martin and Lopez 1999; Sato et al. 2014) and may have to travel greater distances than counterparts in undisturbed habitat to access food, shelter or thermoregulatory resources (Amo et al. 2007). Thus, the continuing creation, expansion, and maintenance of ski runs represent a considerable threat to subalpine reptiles by preventing individuals from dispersing freely throughout the landscape, impeding population connectivity and persistence. However, ski-run networks worldwide often incorporate small-to-large patches of relatively intact forest on, or between, ski runs (Hadley and Wilson 2004; JGR 2010; PBPL 2002; Strong et al. 2002). These vegetated patches may 
be capable of supporting populations of lizards (Bell and Donnelly 2006 and references therein), or alternatively, could be suitable "stepping stones" (Bennett and Saunders 2010; Lindenmayer and Fischer 2006) allowing for movements of reptiles between otherwise disconnected areas of continuous forest in ski resorts. As far as we are aware, the value of these vegetated patches on ski runs for reptiles - or other wildlife - in disturbed subalpine landscapes has not been investigated.

In this paper, we use a detailed case study of a common, generalist reptile species southern grass skink (Pseudemoia entrecasteauxii) - to test critical theories and predictions about the effects of habitat loss and fragmentation in a novel landscape context. Specifically, we investigated whether 1) forest loss; 2) patch size; 3) patch isolation; and 4) increased availability of edge habitat affect patterns of lizard abundance in a modified subalpine landscape.

First, we postulated that forest loss associated with ski run construction would have a negative effect on lizard abundance. Cleared habitats tend to support fewer lizards in a 65 variety of ecosystem types (e.g., forests, D'Cruze and Kumar 2011; agricultural areas, Driscoll 2004; plantations, Fischer et al. 2005; subalpine environments, Sato et al. 2013b), and we expected to observe the same pattern in our study system (i.e., greatly reduced abundances of individuals in the cleared, grassy ski-run matrix compared to forested areas). Second, we postulated that large forested patches would support more lizards than smaller 70 forested patches, which is an implicit assumption of metapopulation theory (Gaggiotti and Hanski 2004). This is because large patches offer a greater abundance of exploitable resources for lizards (assuming uniform habitat quality; Gaggiotti and Hanski 2004; Lindenmayer and Fischer 2006; Michael et al. 2008), and thus have a greater potential carrying capacity than small patches. Third, we postulated that isolated habitat patches on ski runs, far from continuous habitat, would support fewer lizards than less isolated patches. In 
Australia, lizards such as P. entrecasteauxii tend to be dispersal limited (tens of metres; see Clobert et al. 1994; James 1991) and also infrequently use ski runs (Sato et al. 2013b). Combined, these factors are likely to reduce rates of immigration of $P$. entrecasteauxii to isolated patches compared with less isolated patches (Moilanen and Hanski 1998), leading to

80 local population size reductions and eventually localised population extinctions (Eriksson et al. 2014). Finally, we postulated that lizards would be more abundant in edge habitats than the core of forested areas. The altered microclimatic conditions (e.g., increased light penetration that subsequently alters thermal regimes) available in edge habitats may benefit lizards (see Rubio and Simonetti 2011; Schlaepfer and Gavin 2001), encouraging increased use of these habitats. This is particularly the case for basking heliotherms such as $P$. entrecasteauxii (Green and Osborne 2012) that are constrained by highly variable environmental conditions at high elevations (Huang and Tu 2008).

In addition to addressing the four postulates above, we investigated a key potential driver, thermal regimes, which may contribute to the observed patterns of lizard distribution in subalpine ski resorts. Thermal regimes are an important determinant of reptile distribution worldwide (Diaz 1991; Huang et al. 2006) because sufficient warmth and solar radiation is required by these animals to assimilate energy for foraging and reproduction (Avery 1979; Martin et al. 2003). Previously, Sato et al. (2014) found that reduced structural complexity on ski runs can significantly alter thermal regimes, potentially influencing habitat selection and consequently the distribution of lizards. Based on those results, and given that structural complexity and insolation can vary dramatically across grass-forest ecotones (Burt and Rice 2009; Laiolo and Rolando 2005; Shine et al. 2002), we hypothesized that habitat fragmentation would alter the thermal regimes of matrix and patch habitats, and that lizard distribution patterns across these habitats would reflect avoidance of unfavourable thermal environments. Habitats that are too hot may present immediate risks to survival (Spellerberg 
1972), and habitats that are too cold may limit opportunities for energy assimilation (Martin and Lopez 1999).

\section{Methods}

Study species and area

The most abundant lizard species detected in our study area, $P$. entrecasteauxii, occurs commonly in the Australian alpine-subalpine region (Green and Osborne 2012) but has a wider distribution across south-eastern Australia (Wilson and Swan 2008). The species is a small (mean adult snout-vent length $=51.5 \mathrm{~mm}$; mean adult mass $=3.0 \mathrm{~g}$; C. Sato,

110 unpublished data), diurnally-active heliotherm (Green and Osborne 2012) that can tolerate a wide range of body temperatures $\left(\mathrm{T}_{\min }=2.2-2.8^{\circ} \mathrm{C}, \mathrm{T}_{\max }=41.9-42.5^{\circ} \mathrm{C}\right.$; Spellerberg 1972). The species occurs in a wide range of habitat types found in ski resorts, particularly where woody debris is plentiful (Michael and Lindenmayer 2010; Sato et al. 2013b), but tends to avoid highly modified ski runs covered with exotic grass (Sato et al. 2013b). While there is

115 no specific information regarding the dispersal ability and home-range size of this species, studies investigating similar-sized lizards in Australia and elsewhere suggest dispersal capability is limited (<20 m; see James 1991; Melville and Swain 1999; Sumner et al. 2001) and home ranges are relatively small $\left(<500 \mathrm{~m}^{2}\right.$; see Clobert et al. 1994; Olsson and Shine 2003; Turner et al. 1969).

We conducted surveys for $P$. entrecasteauxii at Thredbo ski resort $\left(36^{\circ} 30^{\prime} \mathrm{S} 148^{\circ} 18^{\prime} \mathrm{E}\right.$; Fig. 1a) in Kosciuszko National Park, south-eastern Australia. In this region, during summer, the mean daily solar exposure ranges from $21.4 \mathrm{MJm}^{-2}$ to $25.8 \mathrm{MJm}^{-2}$ and the mean maximum temperature ranges from $19.1^{\circ} \mathrm{C}$ to $21.3^{\circ} \mathrm{C}$ (BOM 2014). During winter, the mean minimum temperatures range from $-2.4^{\circ} \mathrm{C}$ to $-3.8^{\circ} \mathrm{C}$ (BOM 2014). Annual precipitation is 
$>2000 \mathrm{~mm}$ per year, with summers drier than winters (Green and Osborne 2012). The study area is covered with snow typically from mid-June to October.

We selected survey sites $(n=33)$ on south-facing slopes, varying in elevation from $1400 \mathrm{~m}$ to $1785 \mathrm{~m}$. Across this range, vegetation communities in continuous forest and remnant native vegetation on ski runs intergrade from Eucalyptus delegatensis-E. dalrympleana (alpine ash-mountain gum) dominated forest on the lower slopes to $E$. niphophila (snow gum) dominated forests at higher altitudes. The understorey and ground layer of these sites vary in composition but generally have a dense cover including shrubs such as Bossiaea foliosa (leafy bossiaea), Cassinia uncata (sticky cassinia), Hovea montana (mountain hovea) and Olearia phlogopappa (dusty daisy-bush); herbs such as (Acaena novaezelandiae (bidgee widgee), Asperula gunnii (mountain woodruff) and Stellaria pungens (prickly starwort); and grasses such as Poa fawcettiae (smooth blue snowgrass) and Poa costiniana (bog snow-grass); as well as considerable amounts of litter.

Field sites located in the centre of ski runs were dominated by exotic grasses, predominantly Agrostis capillaris (browntop bent) and Festuca rubra (red fescue). These sites all were subject to the same seasonal management practices (slashing and mowing during summer, and winter slope grooming).

\# Figure 1 approximately here\#

145 Sampling design and lizard surveys

To test our first hypothesis regarding effects of habitat type on lizard abundance, we conducted reptile surveys at a series of 'patch' sites $(n=19)$, 'control' sites $(n=7)$ and 'matrix' sites $(n=7)$ across the south facing slopes of Thredbo ski resort. We located 'patch' sites in forested remnants surrounded entirely by highly modified, exotic grass ski runs; 
'control' sites in tracts of continuous, subalpine forest ( $>9$ ha) showing minimal signs of disturbance; and 'matrix' sites in the centre of groomed ski runs cleared of native vegetation and rehabilitated with exotic grasses.

When selecting patch sites, we applied a strict set of criteria so that we could test the effects of size and isolation (i.e., Postulate 2 and Postulate 3) on lizard abundance. We chose patches according to two size classes: small $\left(<450 \mathrm{~m}^{2}\right)$ or large $\left(>500 \mathrm{~m}^{2}\right)$; and two isolation classes based on distance to large ( $>9$ ha) tracts of minimally disturbed, subalpine forest: near $(<25 \mathrm{~m}$ to forest) or isolated ( $>35 \mathrm{~m}$ to forest). We based these cut-offs for size and isolation on the natural history of lizards of similar body size (see James 1991; Melville and Swain 1999; Sumner et al. 2001; Turner et al. 1969). We also ensured sites were separated from one another by $\geq 20 \mathrm{~m}$ to maximise the chances that observations of lizards were independent. Using these selection criteria, we established five replicates of small, near patches; five replicates of small, isolated patches; five replicates of large, isolated patches; and four replicates of large, near patches. More replicates of large, near patches were unavailable because of limitations in the spatial availability of remnant vegetation meeting our criteria.

165 Given the strict set of criteria we applied in selecting sites, the constraints of site availability were such that there was little scope for randomization of site selection.

Within each site (i.e., patch, control or matrix), we established a series of $6 \times 10 \mathrm{~m}$ survey plots to standardise the area surveyed at each site (Fig 1b). For patch sites, we scaled the number of survey plots to the total size of the patch. Accordingly, we surveyed three plots in very large patches $\left(>1600 \mathrm{~m}^{2}\right)$, two plots in large patches $\left(540-1400 \mathrm{~m}^{2}\right)$, and one plot in small patches $\left(290-420 \mathrm{~m}^{2}\right)$. We located plots in these patches $\geq 5 \mathrm{~m}$ from the edge of the nearest ski run and $\geq 10 \mathrm{~m}$ from one another, along a transect that roughly bisected the patch (Fig. 1). For very small patches $\left(<90 \mathrm{~m}^{2}\right)$, we surveyed the entire area. Control and matrix sites far exceeded the size of our largest patch (i.e. $>3500 \mathrm{~m}^{2}$ ), so we established the 
maximum number of survey plots $(n=3)$ in these areas, ensuring that they were separated from one another by $\geq 10 \mathrm{~m}$.

Finally, to test our fourth postulate regarding the effect of edge availability on lizard abundance, we surveyed edge habitats at each patch site. The edge between the vegetated patches and surrounding exotic grass matrix was hard (sensu Forman 1995; see Appendix 1) and microhabitat conditions differed noticeably between forest and exotic-grass ski run (C. Sato, personal observation). We defined edge habitat as the area extending $2 \mathrm{~m}$ into a patch and $3 \mathrm{~m}$ into the exotic-grass ski run (Fig. 1b). We used this 'definition' of an edge based on observations of differences in abiotic characteristics; light penetration decreased markedly within $2 \mathrm{~m}$ of the edge of a patch, and beyond this appeared less variable. This edge definition also allowed us to maximise consistency in the size of plot surveyed between edge habitats and core habitats. Thus, at each patch site, we surveyed one edge plot (5 x $12 \mathrm{~m})$, unless islands were very small $\left(<90 \mathrm{~m}^{2}\right)$, in which case we surveyed the entire edge habitat around the patch.

We conducted reptile surveys during three periods (10 January - 6 February 2011, 10 February - 11 March 2012, and 29 November 2012 - 20 January 2013). At each survey plot, we conducted non-destructive, time- and area-constrained $\left(10 \mathrm{~min} / 60 \mathrm{~m}^{2}\right)$ active searches (a standard survey technique for diurnally active, terrestrial heliotherms; Manning et al. 2013; Michael et al. 2012; Sato et al. 2013b). This method involved systematically moving through a plot searching for lizards around vegetation, rocks, logs, and litter. We recorded all observations of lizards during 10-minute survey periods. At each plot, we completed nine repeat surveys across three survey periods (i.e., three days per survey period, and three survey periods across two field seasons, thus a total of 90 minutes at each site). To maximise chances of detecting lizards, we conducted surveys only on calm, partly sunny to sunny days. Moreover, we randomised the timing of visits to sites to survey 'morning' (0730-1200; 

avoid detectability issues associated with temporal variation in lizard numbers.

Thermal environments

To investigate the effects of habitat fragmentation on thermal regimes, and the effects of thermal environment on lizard distribution patterns, we used temperature loggers (Thermochron i-Buttons, Thermodata Pty Ltd, QLD, Australia; diameter, 17.4 mm; height, $5.9 \mathrm{~mm}$ ) to record ground surface temperatures. At each plot within 'isolated' patches, we deployed two temperature loggers - one on the eastern side of the plot and one on the western side of the plot - to capture the spatial variation in ground surface temperatures available to lizards over their active period (see Tracy and Christian 1986). For edge plots, we placed two temperature loggers at the interface between the vegetated patch and exotic grass matrix. For control and matrix sites, we placed two temperature loggers in the central plot - one on the eastern side and one on the western side. We ensured that all loggers were in contact with the ground (secured in place with a tent peg) and partially covered by grasses or litter to prevent exposure to lengthy periods of direct sunlight.

We programmed all loggers to record temperature every 30 minutes and left the loggers in situ from 1 December to 31 December 2012 - the month of our field season representing median long-term average temperatures for the study area (BOM 2014). After this time, we collected all loggers for analysis.

Statistical analysis

To explore the effects of fragmentation on the number of lizards observed, we fitted Hierarchical Generalised Linear Models (HGLMs; Lee et al. 2006) assuming a quasi-Poisson distribution with a log link function for the response and a gamma distribution with a log link 
function for the random component. We fitted two models for lizard observations. We included the number of lizards observed per survey period as the response variable, and 'Plot' nested within 'Site' as random effects. Additionally, in both models we included 'Survey Period' as a fixed effect, to determine whether the numbers of lizards observed differed between survey periods. We focused our first model on the effect of disturbance (i.e., habitat loss) on the number of lizard observations (Postulate 1), including 'Habitat Type' (i.e., matrix, patch or control) as a fixed effect. We then excluded matrix sites from further analyses of lizard observations because we detected few individuals in the matrix $(n=6$ individuals across all sites and surveys), and the inclusion of these sites in the HGLMs masked the effects of other variables of interest (e.g., patch size and patch isolation). For the second HGLM, we used the three habitat fragmentation attributes identified in our hypotheses as fixed effects: patch size, patch isolation and edge effects ('Forest Location') (Postulates 2 -4). Arguably, differing densities of lizards observed in edge and core habitats of patches could be due to the increased difficulty in detecting lizards in densely vegetated core areas compared with comparatively more open edge habitats. Thus, to determine

240 whether rates of detection differed between edge and core habitats, we fitted N-mixture models for abundance (Royle 2004) assuming a Poisson distribution for the latent abundance using 'unmarked' package (Fiske and Chandler 2011) implemented in R (R Core Team 2013).

To analyse temperature data, we included temperature readings taken between 0500 and 1830 from all sites, when lizards were likely to be active. For these readings, we calculated the mean, absolute maximum, absolute minimum, and range of ground surface temperatures recorded at each data logger over the 31-day period that loggers were deployed. We then used linear mixed models (Harville 1977) to determine whether there were significant differences in the thermal environments of sites. We included 'Habitat Type', 
'Patch Size', and 'Forest Location' (i.e., edge vs. core habitat) as fixed effects, and 'Logger Position' (i.e., eastern or western side of plot) and 'Plot' nested within 'Site' as random effects to account for spatial correlation. We included temperature measures (mean, absolute maximum, absolute minimum, and range of ground surface temperatures) as the response variables.

For temperature data, we also investigated the length of time that ground surface temperatures fell outside the critical body temperature thresholds of $P$. entrecasteauxii (an absolute critical minimum of $2.2^{\circ} \mathrm{C}$ and an absolute critical maximum of $42.5^{\circ} \mathrm{C}$; see Spellerberg 1972). Beyond these temperature limits, lizard locomotion is impaired, and consequently individuals lose the ability to escape from conditions that may lead to their death (Spellerberg 1972). Lizards exposed to ground surface temperatures outside their critical thermal thresholds for more than a few minutes cannot forage for food, escape predation attempts, or endure physiological stresses (Spellerberg 1972).

In summary, we quantified the total number of hours that ground surface temperatures exceeded the absolute critical maximum body temperature, and fell below the absolute critical minimum body temperature, of $P$. entrecasteauxii as a proportion of the total number of hours available for lizard activity (434 hours across 31 days). We then fitted a quasibinomial HGLM to investigate whether the calculated proportion of hours differed between 'Habitat Types' (i.e., matrix, patch and control), which was a fixed effect. To account for the spatial structure, we included 'Plot' nested within 'Site' as random effects. We used GenStat 16 (VSN International Ltd) for all statistical computation.

\section{Results}

Effects of fragmentation 
Across the three survey periods, we recorded 543 P. entrecasteauxii observations. We detected most of these individuals in patches $(n=365)$ and undisturbed forest $(n=172)$. We observed few P. entrecasteauxii in the matrix (i.e., centre of ski runs; $n=6$ ). There was no difference in the number of lizards observed between survey periods $\left(\chi_{2}^{2}=2.395, P=0.302\right)$.

The number of $P$. entrecasteauxii observations differed between habitat types $\left(\chi_{2}^{2}=\right.$ 30.38, $P<0.001$; Fig. 2a), with fewer $P$. entrecasteauxii recorded in the matrix. After we excluded matrix sites from the analysis, we found that patch size did not influence the number of lizards observed $\left(\chi_{1}^{2}=2.806, P=0.246\right)$, but that forest location did. More lizards were observed in edge plots than core plots $\left(\chi_{1}^{2}=38.55, P<0.001\right)$, and more lizards were observed in the edges of vegetated patches near continuous forest than in the edges of patches far from continuous forest, or in the core of any site $\left(\chi_{1}^{2}=4.105, P=0.04\right.$; Fig. 2b). We 285 found no difference in detection rates of lizards between edge and core habitats $(\mathrm{P}=0.45)$.

\#Figure 2 approximately here\#

Thermal environments

We found an interaction between Habitat Type and Forest Location (i.e., edge vs. core habitat) for all measures of ground surface temperature (mean, maximum, minimum, and range; $P<0.001$ for all measures; Table 1). Matrix sites had higher mean, maximum and range of ground surface temperatures than the edge or core of patches, or controls $(P<0.001$ for all measures; Table 1). Additionally, the edges of patches had higher mean, maximum and range of ground temperatures compared with core habitats (Table 1). Conversely, matrix sites had lower minimum ground surface temperatures compared to patches or controls $(P<0.001$; Table 1). 
\# Table 1 approximately here\#

300

The length of time that ground temperatures exceeded the critical maximum body temperatures of lizards $\left(42.5^{\circ} \mathrm{C}\right.$; see Spellerberg 1972) also varied with Habitat Type and Forest Location. Matrix sites had longer periods when ground surface temperatures exceeded the critical maximum body temperatures of lizards compared with either patches or controls (matrix: $0.74 \pm 0.21 \mathrm{~h} \mathrm{day}^{-1}$; patch: $0.17 \pm 0.07 \mathrm{~h} \mathrm{day}^{-1}$; control: $0.03 \pm 0.02 \mathrm{~h} \mathrm{day}^{-1} ; \chi_{2}^{2}=$ 20.28, $P<0.001$; Fig. 3a,c). In terms of edge effects, the ground surface temperature of edge plots exceeded the critical maximum body temperature of lizards for longer periods than core plots, but not as long a period as matrix sites (edge: $0.44 \pm 0.16 \mathrm{~h} \mathrm{day}^{-1}$, core: $0.01 \pm 0.01 \mathrm{~h}$ day $^{-1}$, matrix: $0.74 \pm 0.21 \mathrm{~h}_{\text {day }^{-1}} ; \chi_{1}^{2}=5.81, P=0.016$; Fig. $3 \mathrm{~b}$ ). temperatures of lizards $\left(2.2^{\circ} \mathrm{C}\right.$; see Spellerberg 1972) did not differ among Habitat Type $\left(\chi_{2}^{2}=0.8849, P=0.642\right)$ or Forest Location $\left(\chi_{1}^{2}=0.4796, P=0.489\right)$.

\#Figure 3 approximately here\#

\section{Discussion}

Despite the considerable threat that habitat degradation poses to reptile populations (Todd et al. 2010), research investigating effects of ski run construction on reptiles has been limited (Sato et al. 2013a), particularly regarding how fragmentation affects reptile distributions and whether this may be driven by alterations to thermal environments. We found that both thermal environments and lizard abundance were affected by fragmentation. Maximum and mean ground temperatures were higher in the matrix (i.e., the centre of exotic grass ski runs), and exceeded the critical maximum body temperature of lizards for longer 
periods, than in forested areas (patches or controls). Similarly, edge habitats were warmer than core habitats of forested areas. Observations of lizards appeared to correspond with these thermal gradients; we observed lizards infrequently in the matrix, but recorded them in remnant forested patches on ski-run networks (supporting Postulate 1). We detected more lizards at the edges of patches near controls (i.e., continuous forest) than at the edges of patches far from controls, or in the core of any forested area (supporting Postulate 3 and substantiating Postulate 4). Patch size did not appear to influence lizard abundance (refuting Postulate 2).

Based on our findings, we argue that the creation of ski runs, through the removal of large tracts of native vegetation and structural habitat features, has a negative effect on lizard distributions (see also Sato et al. 2013b). This effect is likely due to the limited structural complexity available on ski runs, which in turn limits available resources for basking, shelter from predators, or refugia from extreme ground surface temperatures (Sato et al. 2014; Fig. 3). Without these resources, the immediate and long-term survival of lizards in these areas could be greatly reduced. However, retaining remnant patches on these ski runs may, in part, mitigate the negative effects of habitat loss on lizard populations. Regardless of patch size, remnant patches are capable of supporting lizards in similar densities to undisturbed forest (Fig. 2). Thus, remnant patches are important design features in ski resorts that may facilitate the persistence of lizards in modified subalpine landscapes.

One reason for the similarities in lizard densities between undisturbed forest and remnant vegetation patches is the increased availability of edge habitat for lizards occupying remnant patches. Edge habitats provide benefits to fragmented lizard populations through altered microclimates (e.g., increased sunlight, decreased humidity, higher temperatures; see Collinge 1996 ). The altered microclimatic conditions allow lizards at high elevations to maximise thermoregulatory opportunities and energy assimilation (Angilletta 2001; Huang et 
al. 2013) in an environment where conditions are extreme and highly variable (Carrascal and Diaz 1989; Huang and Tu 2008). Our results strongly suggest that lizards may be selecting edge habitats over all other available habitats; it was in the edges of remnant patches where we observed the highest number of $P$. entrecasteauxii across all habitat types (Fig. 2). This selection is likely due to the optimal thermal qualities of these environments. Edges are warmer than core habitats but cooler than exotic grass ski runs, providing lizards with increased thermoregulatory opportunities.

Edges also may provide preferred habitat for lizards because, in addition to improved thermal conditions, refuges from predators are close to basking sites. The proximity of refuges may increase the probability of escaping a predator (Greene 1988; Martin and Lopez 1999), and also can result in improved body condition (and consequently fitness) when compared with conspecifics that travel greater distances to find shelter (Amo et al. 2007). Thus, the combination of favourable thermal regimes and proximity to shelter sites provided by vegetated patches on ski runs could offer lizards suitable environments for extended periods of 'risk-minimised' basking. While we did not quantify the influence of interacting factors such as predation risk and structural complexity on lizard habitat choices, this would be an interesting avenue of future research that could further explain the patterns of lizard distribution in subalpine environments affected by ski resort developments.

Despite the benefits derived from edge habitats in remnant patches, the degree to which edges of remnant patches, and the remnant patches themselves, can mitigate the negative effects of initial habitat loss on lizard populations is likely to be highly dependent upon the isolation of those patches. Patch isolation is likely to influence the abundance and ultimately the probability of local population extinction of reptiles. This is because the matrix remains largely unused by lizards due to a combination of extreme thermal conditions and increased rates of predation (Sato et al. 2014). Hence, as vegetated patches become more 
isolated from continuous forest (i.e., as individual ski runs are widened or entire ski-run networks are expanded), it is likely that dispersal will be restricted or potentially prohibited altogether, as in other ecosystems (Dixo and Metzger 2009; Munguia-Vega et al. 2013). The further lizards must travel across inhospitable, exotic grass ski runs to reach vegetated patches, the more likely they will be preyed upon (Sato et al. 2014), suffer from heat stress due to extreme thermal conditions (Spellerberg 1972), or progressively lose body condition if multiple movements occur across a season (Amo et al. 2007). As a consequence, rates of immigration and colonization to more isolated patches will be reduced, preventing boosts to local populations and increasing extinction risk (Gaggiotti and Hanski 2004). While lizards were not absent from isolated patches in our study, the abundance of lizards was reduced in these areas, even in the edge habitats of these patches, compared with less isolated patches. Hence, lizards may be unwilling or incapable of frequently crossing ski runs.

Implications for management

First and foremost, we argue that it is essential, wherever possible, to retain undisturbed native vegetation and other elements of structural complexity (such as rocks and $\operatorname{logs}$ ) to facilitate the persistence of lizards in disturbed subalpine environments. However, retention of structural complexity on ski runs often directly compromises the safety of skiers and snowboarders (Kelsall and Finch 1996), so it is not always possible to conserve structural complexity. In such cases, we contend that careful design and management of ski runs, in a way that decreases isolation of suitable habitat patches, will assist the continued dispersal of lizards between habitat patches, thus reducing landscape-scale extinction risk. The distances between vegetated patches on ski runs and continuous forest can be minimised in several ways. First, for narrow ski runs $(<20 \mathrm{~m})$, buffering the edges of runs with native vegetation (e.g., low heath species that are unlikely to impede skier activity) will reduce the width of the 
exotic grass matrix. Heath vegetation should provide sufficient structural complexity to attenuate extreme ground surface temperatures, and potentially provide sufficient cover to reduce rates of predation on lizards crossing ski runs (Sato et al. 2014). Second, for wide exotic grass ski runs $(>40 \mathrm{~m})$, the distances between forested areas could be minimised through planting patches of native forest species on the runs (in addition to buffering ski run edges with native vegetation). Such plantings would break up the extent of the exotic grass matrix, potentially allowing lizards to inhabit the new patches, or to use them as 'stepping stones' to larger patches of forest (Bennett and Saunders 2010; Lindenmayer and Fischer 2006). Finally, connections between suitable habitat patches could be restored by reintroducing structural habitat features onto ski runs such as semi-submerged rocks or timber, similar in design to the wildlife crossings used for the threatened Burramys parvus (mountain pygmy possum; Mansergh and Scotts 1989), which may need to be relocated before each winter. However, the efficacy of wildlife crossings for reptiles needs to be investigated before broad-scale implementation across ski resorts.

415 Acknowledgments This research was supported by the Glenn Sanecki Alpine Ecology Scholarship. Ethical approval was provided by The Australian National University, Animal Experimentation Ethics Committee (Protocol No. S.RE.11.10), and approval to work within Kosciuszko National Park was provided by the Department of Environment and Conservation (Scientific Investigation Licence No. S13155). We thank L. Rayner for assisting with reptile surveys and for reviewing an earlier version of the manuscript, and the Thredbo Ski Resort Staff for providing transport around the mountain. 
Table 1 Mean, maximum, minimum and range of temperatures recorded (with average standard errors of differences; 'S.E.D') in the matrix (M), edges of patches (EP), core of patches $(\mathrm{CP})$ and controls $(\mathrm{F})$

\begin{tabular}{|c|c|c|c|c|}
\hline & \multicolumn{4}{|c|}{ Temperature Measure $\left({ }^{\circ} \mathrm{C}\right)$} \\
\hline & Mean & Maximum & Minimum & Range \\
\hline \multicolumn{5}{|l|}{ Plot Type } \\
\hline M & 22.4 & 37.6 & 5.4 & 32.2 \\
\hline EP & 17.4 & 31.8 & 6.2 & 25.6 \\
\hline $\mathrm{CP}$ & 13.8 & 21.0 & 6.7 & 14.3 \\
\hline $\mathrm{F}$ & 14.5 & 24.0 & 6.4 & 17.7 \\
\hline S.E.D & 0.70 & 1.93 & 0.36 & 1.96 \\
\hline Wald Statistic & $\chi_{1}^{2}=76.80^{*}$ & $\chi_{1}^{2}=66.32 *$ & $\chi_{1}^{2}=21.54^{*}$ & $\chi_{1}^{2}=71.49^{*}$ \\
\hline
\end{tabular}


Fig. 1 a) Map of the study region within Kosciuszko National Park (“K.N.P”). The “ $”$ represents Thredbo ski resort. b) Schematic diagram of survey design for forested patches on ski runs. White boxes indicate core plots, hatched boxes indicate edge plots

Fig. 2 Estimated mean number of $P$. entrecasteauxii observations ( $\pm \mathrm{SE})$ in: a) three habitat types: control, patch and matrix; and b) the edge and core of near patches, far patches and the core of undisturbed forest (controls). All estimates are given on the natural scale

Fig. 3 Estimated mean proportion of time $( \pm S E)$ that ground surface temperatures exceeded the critical maximum body temperature $\left(T_{b}\right)$ of lizards in three habitat types: a) control, patch and matrix; and b) core habitat, edge habitat and matrix; c) Mean ( \pm SE) absolute maximum ground surface temperatures $\left({ }^{\circ} \mathrm{C}\right)$ recorded in matrix sites, patches (edge and core), and controls across 31 days, during lizard activity periods. The dashed horizontal line represents the absolute critical maximum body temperature of $P$. entrecasteauxii recorded by Spellerberg (1972) 


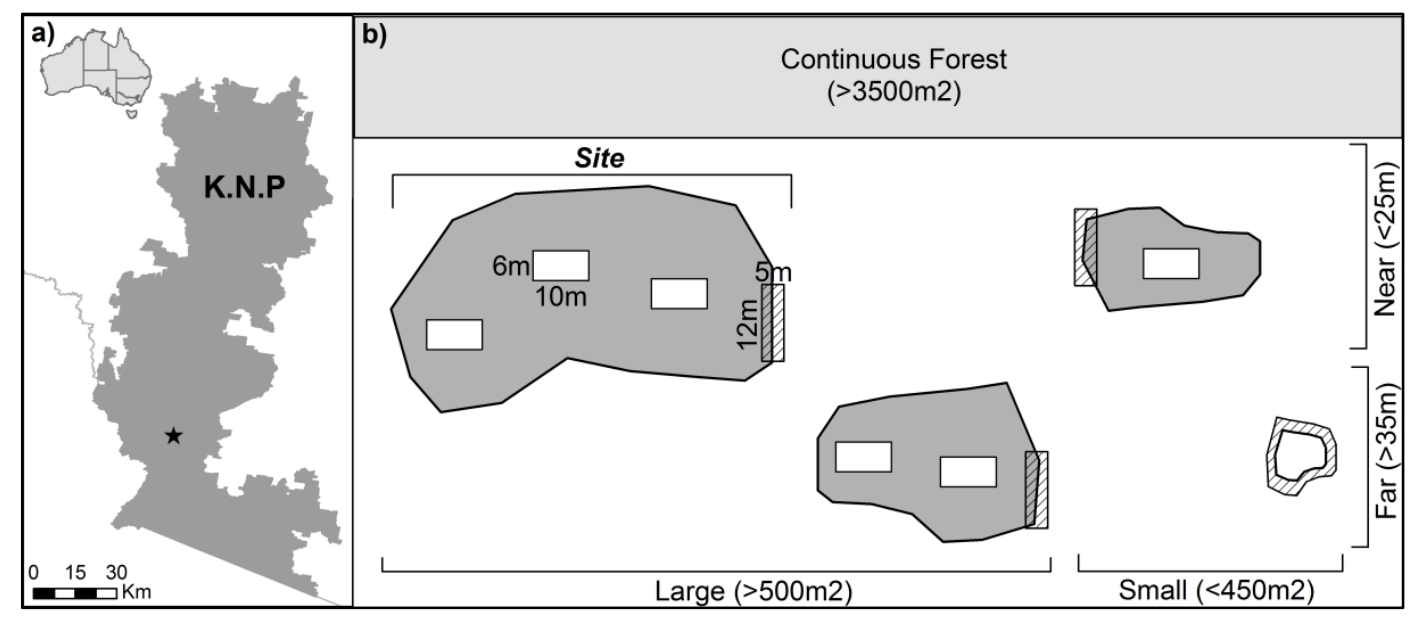

Figure 1. 

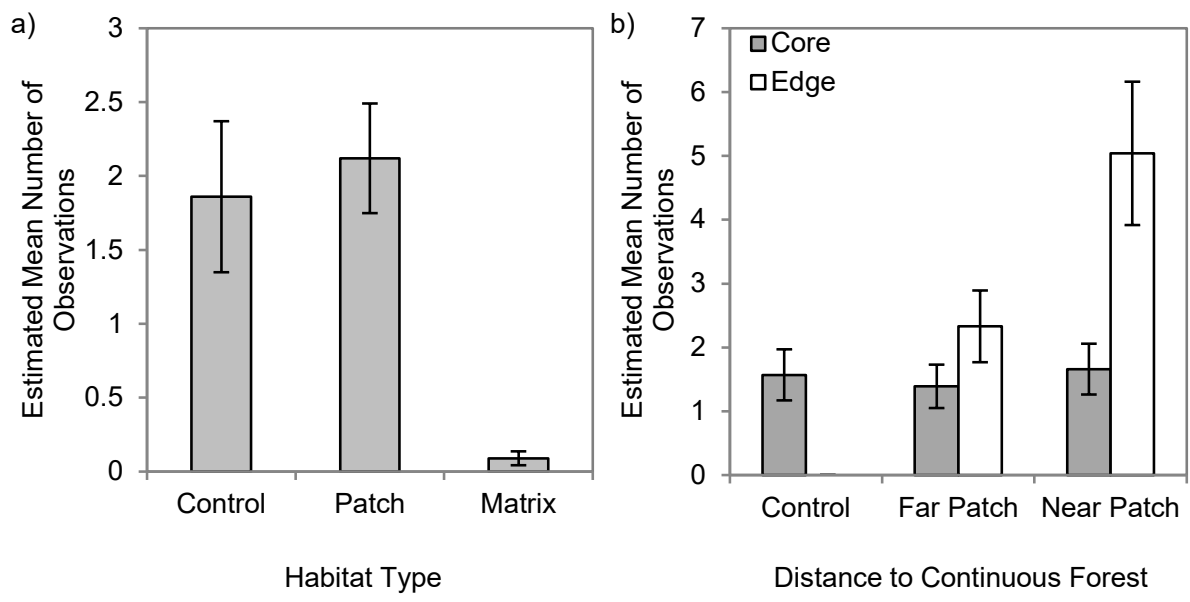

Figure 2. 

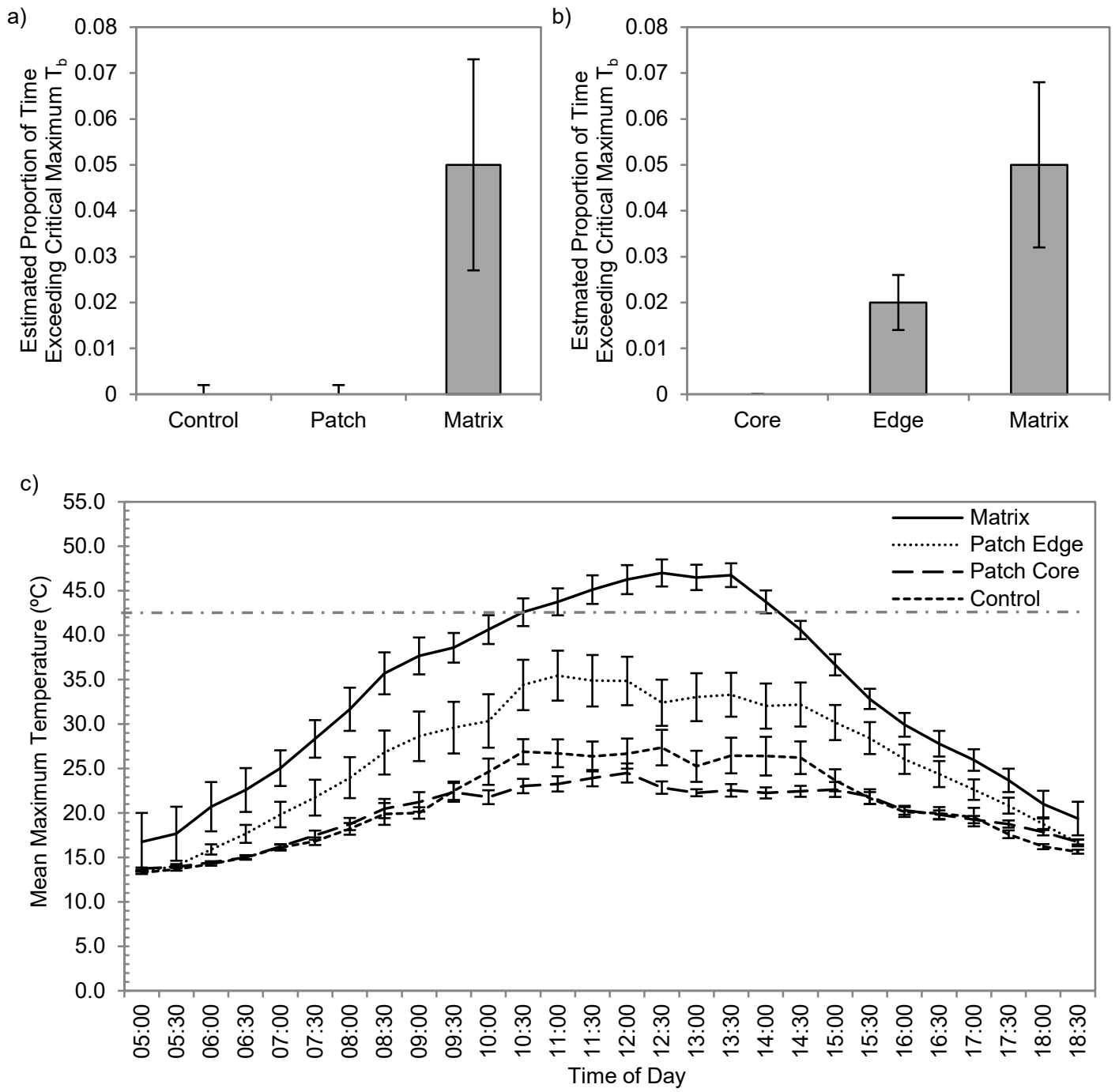

Figure 3. 


\section{References}

Amo L, Lopez P, Martin J (2007) Habitat deterioration affects body condition of lizards: A behavioral approach with Iberolacerta cyreni lizards inhabiting ski resorts. Biol Conserv 135:77-85

Angilletta MJ (2001) Thermal and physiological constraints on energy assimilation in a widespread lizard (Sceloporus undulatus). Ecology 82:3044-3056

Avery RA (1979) Lizards: A Study in Thermoregulation. Thomson Litho Ltd., East Kilbride

Behan MJ (1983) The suitability of commercially available grass species for revegetation of Montana Ski Area. J Range Manage 36:565-567

Bell KE, Donnelly MA (2006) Influence of forest fragmentation on community structure of frogs and lizards in northeastern Costa Rica. Conserv Biol 20:1750-1760

Bennett AF, Saunders DA (2010) Habitat fragmentation and landscape change. In:

Sodhi N. S. and Ehrlich P. R. (eds), Conservation Biology for All. Oxford University Press, New York, pp. 88-106

BOM [Australian Bureau of Meteorology] (2014) Climate statistics for Australian locations: Thredbo Village. Commonwealth of Australia, Available from http://www/bom.gov.au/climate/averages/tables/cw_071041.shtml (accessed 21/02/2014) Burt JW, Rice KJ (2009) Not all ski slopes are created equal: Disturbance intensity affects ecosystem properties. Ecol Appl 19:2242-2253

Carrascal LM, Diaz JA (1989) Thermal ecology and spatio-temporal distribution of the mediterranean lizard Psammodromus algirus. Holarct Ecol 12:137-143

Clobert J, Massot M, Lecomte J, Sorci G, de Fraipont M, Barbault R (1994) 
Pianka E. R. (eds), Lizard Ecology: Historical and Experimental Perspectives. Princeton University Press, Princeton, pp. 183-206

Collinge SK (1996) Ecological consequences of habitat fragmentation: Implications for landscape architecture and planning. Landsc Urban Plan 36:59-77

D'Cruze N, Kumar S (2011) Effects of anthropogenic activities on lizard communities in northern Madagascar. Anim Conserv 14:542-552

Diaz JA (1991) Temporal patterns of basking behavior in a mediterranean lacertid lizard. Behaviour 118:1-14

Dixo M, Metzger JP (2009) Are corridors, fragment size and forest structure 485 important for the conservation of leaf-litter lizards in a fragmented landscape? Oryx 43:435442

Driscoll DA (2004) Extinction and outbreaks accompany fragmentation of a reptile community. Ecol Appl 14:220-240

Eriksson A, Elías-Wolff F, Mehlig B, Manica A (2014) The emergence of the rescue 490 effect from explicit within- and between-patch dynamics in a metapopulation. Proceedings of the Royal Society B: Biological Sciences 281

Fahrig L (2003) Effects of habitat fragmentation on biodiversity. Annu Rev Ecol Evol Syst 34:487-515

Fischer J, Lindenmayer DB, Barry S, Flowers E (2005) Lizard distribution patterns in 495 the Tumut fragmentation "natural experiment" in south-eastern Australia. Biol Conserv $123: 301-315$

Fiske I, Chandler, R (2011) unmarked: An R package for fitting hierarchical models of wildlife occurrence and abundance. J Stat Softw 43:1-23 
Cambridge University Press, Cambridge

Gaggiotti O, Hanski I (2004) Mechanisms of population extinction. In: Gaggiotti O. and Hanski I. (eds), Ecology, Genetics, and Evolution of Metapopulations. Elsevier, Oxford, pp. $337-366$

Green K, Osborne WS (2012) Field Guide to Wildlife of the Australian SnowCountry. Reed New Holland, Sydney

Greene HW (1988) Antipredator mechanisms in reptiles. In: Gans C. and Huey R. B. (eds), Biology of the Reptilia, vol. 16. John Wiley and Sons, New York, pp. 1-152

Hadley GL, Wilson KR (2004) Patterns of small mammal density and survival following ski-run development. J Mammal 85:97-104

Harville DA (1977) Maximum likelihood approaches to variance component estimation and to related problems. J Am Stat Assoc 72:320-338

Huang SP, Chiou CR, Lin TE, Tu MC, Lin CC, Porter WP (2013) Future advantages in energetics, activity time, and habitats predicted in a high-altitude pit viper with climate warming. Funct Ecol 27:446-458

Huang SP, Hsu YY, Tu MC (2006) Thermal tolerance and altitudinal distribution of two Sphenomorphus lizards in Taiwan. J Therm Biol 31:378-385

Huang SP, Tu MC (2008) Heat tolerance and altitudinal distribution of a mountainous lizard, Takydromus hsuehshanensis, in Taiwan. J Therm Biol 33:48-56

James CD (1991) Population-dynamics, demography, and life-history of sympatric scincid lizards (Ctenotus) in central Australia. Herpetologica 47:194-210

JGR [Glacier Resorts Ltd.] (2010) Jumbo Glacier Resort Master Plan. Available from http://www.for.gov.bc.ca/mountain_resorts/resort_plans/approved/Jumbo.htm (accessed 23/09/2013) 

for alpine skiing. Report No. 99. Monash University Accident Research Centre, Clayton Laiolo P, Rolando A (2005) Forest bird diversity and ski-runs: A case of negative edge effect. Anim Conserv 8:9-16

Lee Y, Nelder JA, Pawitan Y (2006) Generalized Linear Models with Random Effects: Unified Analysis via H-likelihood. Chapman \& Hall/CRC, Boca Raton

Lindenmayer D, Fischer J (2006) Habitat Fragmentation and Landscape Change: An Ecological and Conservation Synthesis. Island Press, Washington

Manning AD, Cunningham RB, Lindenmayer DB (2013) Bringing forward the benefits of coarse woody debris in ecosystem recovery under different levels of grazing and vegetation density. Biol Conserv 157:204-214

Mansergh IM, Scotts DJ (1989) Habitat continuity and social organization of the Mountain Pygmy Possum restored by tunnel. J Wildl Manage 53:701-707

Martin J, Lopez P (1999) When to come out from a refuge: Risk-sensitive and statedependent decisions in an alpine lizard. Behav Ecol 10:487-492

Martin J, Lopez P, Cooper WE (2003) When to come out from a refuge: Balancing predation risk and foraging opportunities in an alpine lizard. Ethology 109:77-87

Martin K (2013) The ecological values of mountain environments and wildlife. In: Rixen C. and Rolando A. (eds), The Impacts of Skiing and Related Winter Recreational Activities on Mountain Environments. Bentham E-Books, online, pp. 3-29

Melville J, Swain R (1999) Home-range characteristics of an alpine lizard, Niveoscincus microlepidotus (Scincidae), on Mount Wellington, southern Tasmania Wildl Res 26:263-270

Michael D, Lindenmayer D (2010) Reptiles of the NSW Murray Catchment: A Guide to their Identification, Ecology and Conservation. CSIRO Publishing, Collingwood 
use of active searches and artificial refuges to survey reptiles in temperate eucalypt woodlands. Wildl Res 39:149-162

Michael DR, Cunningham RB, Lindenmayer DB (2008) A forgotten habitat? Granite inselbergs conserve reptile diversity in fragmented agricultural landscapes. J Appl Ecol $45: 1742-1752$

Moilanen A, Hanski I (1998) Metapopulation dynamics: Effects of habitat quality and landscape structure. Ecology 79:2503-2515

Munguia-Vega A, Rodriguez-Estrella R, Shaw WW, Culver M (2013) Localized extinction of an arboreal desert lizard caused by habitat fragmentation. Biol Conserv 157:1120

Nagy L, Grabherr G (2009) The Biology of Alpine Habitats. Oxford University Press, New York

Negro M, Novara C, Bertolino S, Rolando A (2013) Ski-pistes are ecological barriers to forest small mammals. Eur J Wildl Res 59:57-67 lizard, Niveoscincus microlepidotus. Biol J Linn Soc 79:277-283

PBPL [Perisher Blue Pty Ltd] (2002) Perisher Blue Ski Resort Ski Slope Master Plan. Perisher Blue Pty Ltd, Perisher Valley

R Core Team (2013) R: A language and environment for statistical computing. R 570 Foundation for Statistical Computing, Vienna, Austria. Available from http://www.rproject.org/ (accessed 20/05/2014)

Ries JB (1996) Landscape damage by skiing at the Schauinsland in the Black Forest, Germany. Mt Res Dev 16:27-40 
Royle JA (2004) N-Mixture Models for Estimating Population Size from Spatially

575

580

585

590

595

Replicated Counts. Biometrics 60:108-115

Rubio AV, Simonetti JA (2011) Lizard assemblages in a fragmented landscape of central Chile. Eur J Wildl Res 57:195-199

Sato CF, Wood JT, Lindenmayer DB (2013a) The effects of winter recreation on alpine and subalpine fauna: A systematic review and meta-analysis. PlosOne 8:e64282

Sato CF, Wood JT, Schroder M, Green K, Michael DR, Lindenmayer DB (2013b)

The impacts of ski resorts on reptiles: a natural experiment. Anim Conserv doi: 10.1111/acv.12095

Sato CF, Wood JT, Schroder M et al (2014) An experiment to test key hypotheses of the drivers of reptile distribution in subalpine ski resorts. J Appl Ecol 51:13-22

Schlaepfer MA, Gavin TA (2001) Edge effects on lizards and frogs in tropical forest fragments. Conserv Biol 15:1079-1090

Shine R, Barrott EG, Elphick MJ (2002) Some like it hot: Effects of forest clearing on nest temperatures of montane reptiles. Ecology 83:2808-2815

Spehn EM, Rudmann-Maurer K, Körner C, Maselli D (2010) Mountain biodiversity and global change. GMBA-DIVERSITAS, Basel

Spellerberg IF (1972) Temperature tolerances of southeast Australian reptiles examined in relation to reptile thermoregulatory behavior and distribution. Oecologia 9:23-46

Strong AM, Rimmer CC, McFarland KP, Hagen K (2002) Effects of mountain resorts on wildlife. Vermont Law Review 26:689-716

Sumner J, Rousset F, Estoup A, Moritz C (2001) 'Neighbourhood' size, dispersal and density estimates in the prickly forest skink (Gnypetoscincus queenslandiae) using individual genetic and demographic methods. Mol Ecol 10:1917-1927 
Todd BD, Willson JD, Gibbons JW (2010) The global status of reptiles and causes of their decline. In: Sparling D. W., Linder G., Bishop C. A., Krest S. (eds), Ecotoxicology of 600 Amphibians and Reptiles, Second Edition. CRC Press, Florida, pp. 47-67

Tracy CR, Christian KA (1986) Ecological relations among space, time, and thermal niche axes. Ecology 67:609-615

Turner FB, Jennrich RI, Weintrau JD (1969) Home ranges and body sizes of lizards. Ecology 50:1076-1081 duration in the Australian Alps. Clim Change 32:447-479

Wilson S, Swan G (2008) A Complete Guide to Reptiles of Australia. New Holland, Sydney

WWF [World Wide Fund for Nature] (2005) Ecoregion Conservation Plan for the 610 Alps. WWF European Alpine Program, Bellinzona 
Appendix 1. Example of a vegetated patch with hard edges on an exotic grass ski run at Thredbo ski resort.

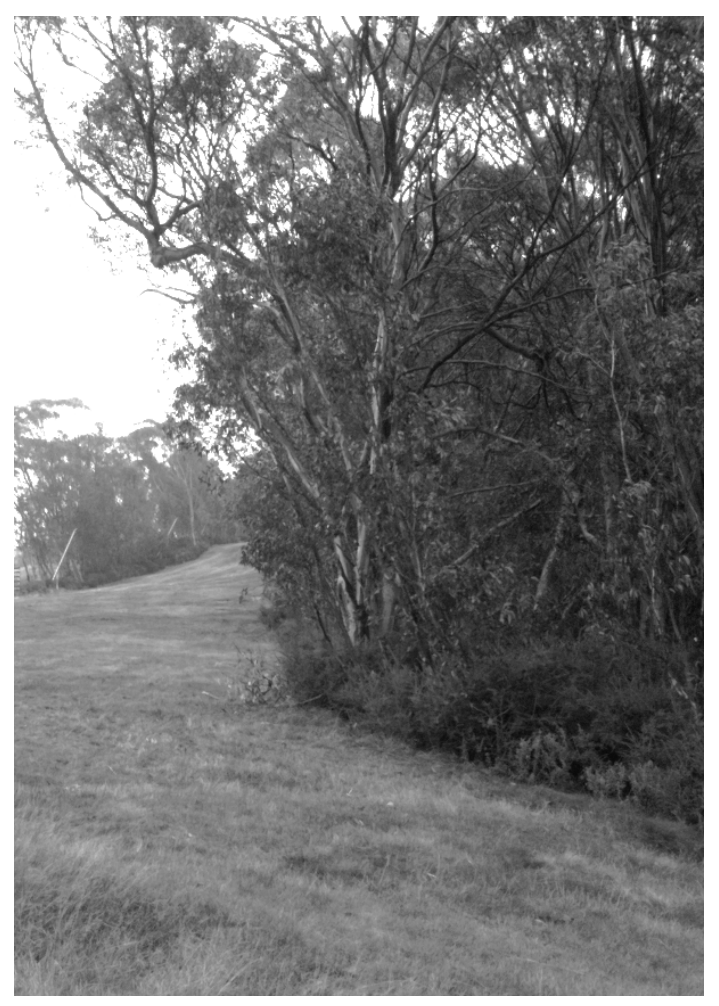

